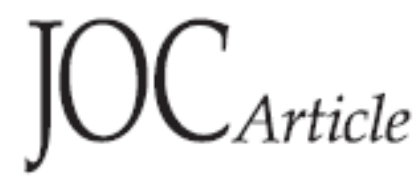

\title{
Equilibrating Dynamic [2]Rotaxanes
}

\author{
Philip C. Haussmann, Saeed I. Khan and J. Fraser Stoddart * \\ California NanoSystems Institute and Department of Chemistry and Biochemistry, University of \\ California, \\ Los Angeles, 405 Hilgard Avenue, Los Angeles, CA 90095-1569, USA \\ stoddart@chem.ucla.edu \\ Received $x x x x, x \times x x$
}

\section{Table of Contents}

$\begin{array}{ll}\text { Introduction } & \mathrm{S} 2\end{array}$

$\begin{array}{ll}\text { Experimental } & \text { S2 }\end{array}$

${ }^{1} \mathrm{H}_{\mathrm{NMR}}$ Spectra of $\mathbf{2}-\mathrm{H} \cdot \mathrm{PF}_{\mathbf{6}}$ and $\mathbf{4 - H} \cdot \mathbf{P F}_{\mathbf{6}} \quad \mathrm{S} 4$

2D-NOESY ${ }^{1} \mathbf{H}$ NMR Spectrum of 3-H·PF 6

VT ${ }^{1}$ H NMR Spectroscopic Data and Methods $\quad$ S6

$\begin{array}{ll}\text { Crystal Structure Packing Diagram } & \text { S7 }\end{array}$

$\begin{array}{ll}\text { References } & \text { S8 }\end{array}$ 


\section{Introduction}

In this supplement, we present experimental details of [2]rotaxane formation and further evidence of a [2] rotaxane architecture for compound $3-\mathrm{H} \cdot \mathrm{PF}_{6}$ in the form of a $2 \mathrm{D}$ NOESY ${ }^{1} \mathrm{H}$ NMR spectrum. ${ }^{\mathrm{S} 1}$ Methods employed and data obtained from a variable temperature ${ }^{1} \mathrm{H}$ NMR spectroscopic investigation, including a table of all measured association constants, are contained herein. The packing diagram associated with the Xray crystal structure of the $[2+2]$ macrocyclic member of the dynamic combinatorial library (DCL), surprisingly formed from a complex mixture containing $1-\mathrm{H} \cdot \mathrm{PF}_{6}$, the DCL, and $\mathbf{3}-\mathrm{H} \cdot \mathrm{PF}_{6}$, is also recorded herein.

\section{Experimental}

General: All reagents and starting materials were used without further purification. Dumbbells 1-H. $\mathrm{PF}_{6}{ }^{\mathrm{S} 2}$ and $2-\mathrm{H} \cdot \mathrm{PF}_{6}{ }^{\mathrm{S} 3}$ were synthesized according to literature procedures. Deuterated solvents for NMR spectroscopic analyses were used as received. Unless otherwise noted, all NMR spectra were recorded at room temperature in a 2:1 mixture of $\mathrm{CD}_{2} \mathrm{Cl}_{2}: \mathrm{CD}_{3} \mathrm{CN}$ on a $500 \mathrm{MHz}$ spectrometer, with a working frequency of $500.13 \mathrm{MHz}$

for ${ }^{1} \mathrm{H}$ nuclei. The residual solvent peak for $\mathrm{CD}_{3} \mathrm{CN}$ at $1.93 \mathrm{ppm}$ was taken as a reference. High resolution ESI mass spectra were recorded on a 7T FTICR instrument.

Synthesis of the Dynamic Combinatorial Library (DCL in Scheme S1): 2,6Diformylpyridine (973 mg, $7.20 \mathrm{mmol}$ ) and 2,2'-oxybis(ethylamine) (750 mg, 7.20 mmol) were heated under reflux in $150 \mathrm{~mL}$ PhMe under Dean-Stark conditions overnight. The crude reaction mixture was cooled, filtered and the solvent evaporated to furnish $1.456 \mathrm{~g}(99 \%)$ of the DCL as a brown solid which was used directly in the synthesis of [2]rotaxanes without further purification. 


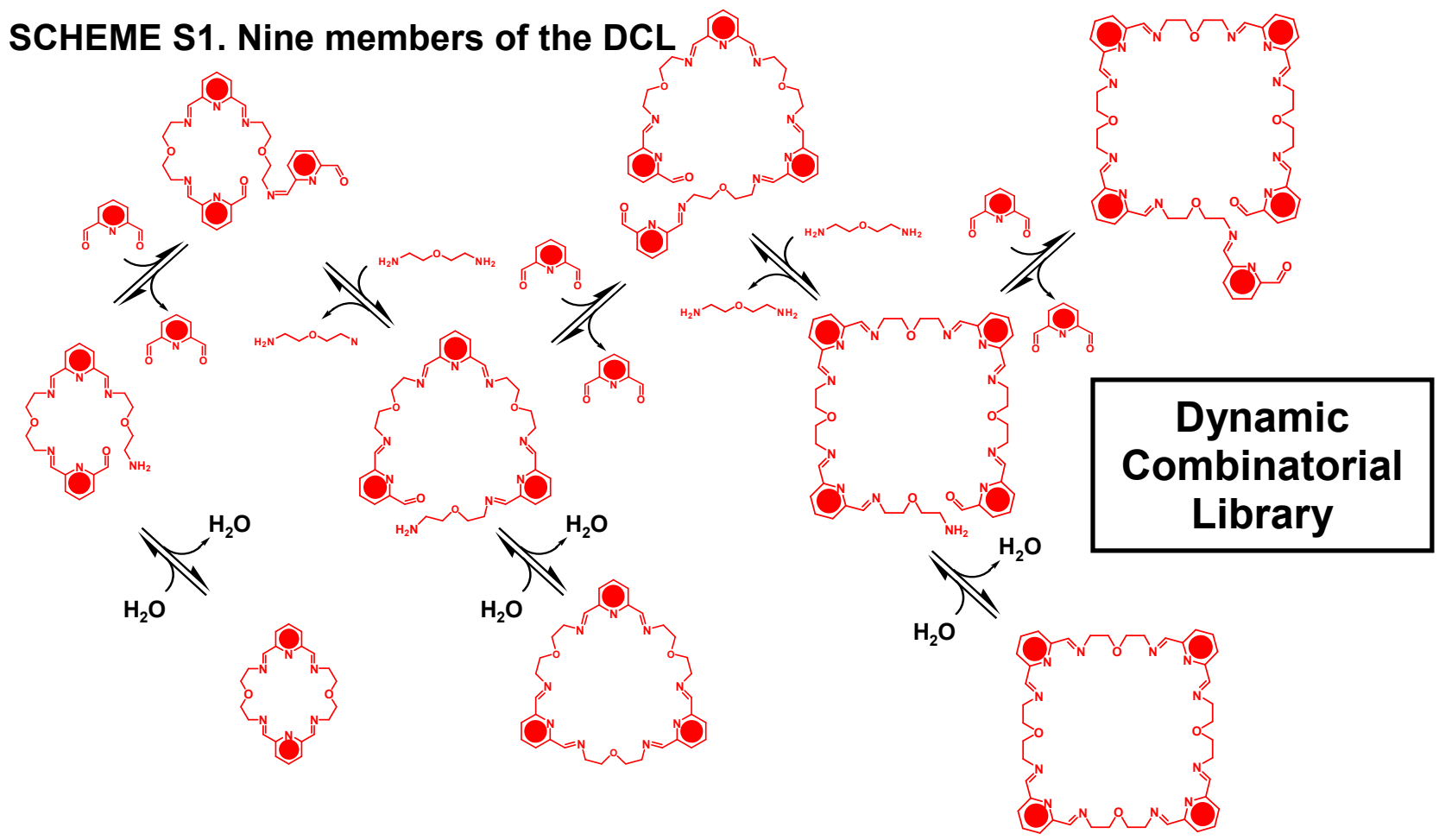

General synthesis of rotaxanes. An appropriate dumbbell compound $(0.01 \mathrm{mmol})$ in $\mathrm{CD}_{2} \mathrm{Cl}_{2}(0.30 \mathrm{~mL})$ and $\mathrm{CD}_{3} \mathrm{CN}(0.15 \mathrm{~mL})$ was added to the DCL $(0.01 \mathrm{mmol})$ in $\mathrm{CD}_{2} \mathrm{Cl}_{2}$ $(0.30 \mathrm{~mL})$ and $\mathrm{CD}_{3} \mathrm{CN}(0.15 \mathrm{~mL})$. The reaction was followed by ${ }^{1} \mathrm{H}$ NMR spectroscopy.

3-H•PF : The ${ }^{1} \mathrm{H}$ NMR spectrum recorded from a mixture that also included the DCL

SCHEME S2. The template-directed synthesis of the [2]rotaxanes $3-\mathrm{H} \cdot \mathrm{PF}_{6}$ and

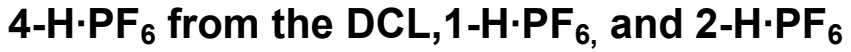

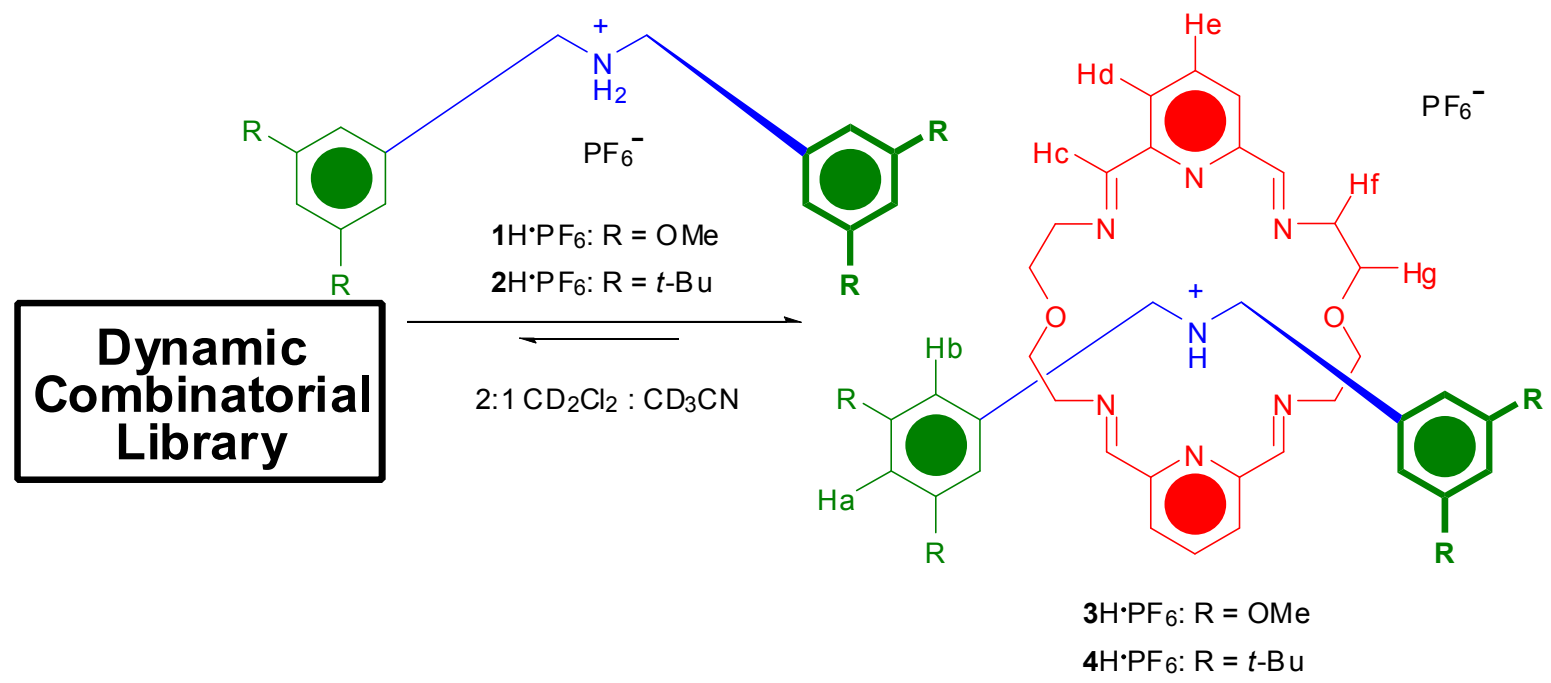


and 1-H·PF $: \delta=9.92-9.84(\mathrm{br} \mathrm{s}, 2 \mathrm{H}), 8.37(\mathrm{~s}, 4 \mathrm{H}), 7.88(\mathrm{t}, J=7.8 \mathrm{~Hz}, 2 \mathrm{H}), 7.60(\mathrm{~d}, J=$ $7.8 \mathrm{~Hz}, 4 \mathrm{H}), 6.32(\mathrm{~d}, J=2.3 \mathrm{~Hz}, 4 \mathrm{H}), 6.15(\mathrm{t}, J=2.3 \mathrm{~Hz}, 2 \mathrm{H}), 4.45(\mathrm{~m}, 4 \mathrm{H}), 3.80-3.69$ (m, $16 \mathrm{H}), 3.51(\mathrm{~s}, 12 \mathrm{H})$; MS(ESI): $m / z$ calcd for $\mathrm{C}_{40} \mathrm{H}_{50} \mathrm{~N}_{7} \mathrm{O}_{6}\left[\mathrm{M}-\mathrm{PF}_{6}\right]^{+}:$724.3823, found 724.3844 .

4-H•PF : The ${ }^{1} \mathrm{H}$ NMR spectrum recorded from a mixture that also included the $\mathbf{D C L}$ and 2-H·PF $: \delta=9.95-9.84($ br s, $2 \mathrm{H}), 8.40(\mathrm{~s}, 4 \mathrm{H}), 7.88(\mathrm{t}, J=7.8 \mathrm{~Hz}, 2 \mathrm{H}), 7.62(\mathrm{~d}, J=$ $7.8 \mathrm{~Hz}, 4 \mathrm{H}), 7.17$ (t, $J=1.8 \mathrm{~Hz}, 2 \mathrm{H}), 6.97$ (d, $J=1.8 \mathrm{~Hz}, 4 \mathrm{H}), 4.54$ (m, 4H), 3.69 (m, $8 \mathrm{H}), 3.64(\mathrm{~m}, 8 \mathrm{H}), 1.06(\mathrm{~s}, 32 \mathrm{H}) ; \mathrm{MS}(\mathrm{ESI}): \mathrm{m} / \mathrm{z}$ calcd for $\mathrm{C}_{52} \mathrm{H}_{74} \mathrm{~N}_{7} \mathrm{O}_{2}\left[\mathrm{M}-\mathrm{PF}_{6}\right]^{+}$: 828.5904, found 828.6018.

\section{${ }^{1} \mathrm{H}$ NMR Spectra of $2-\mathrm{H} \cdot \mathrm{PF}_{6}$ and $4-\mathrm{H} \cdot \mathrm{PF}_{6}$}

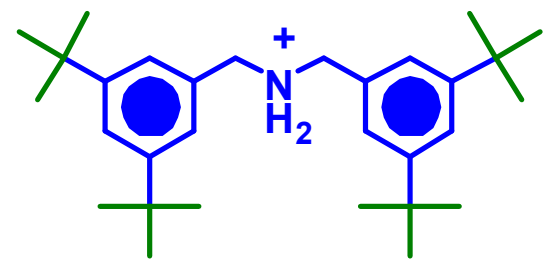

$2-\mathrm{H} \cdot \mathrm{PF}_{6}$

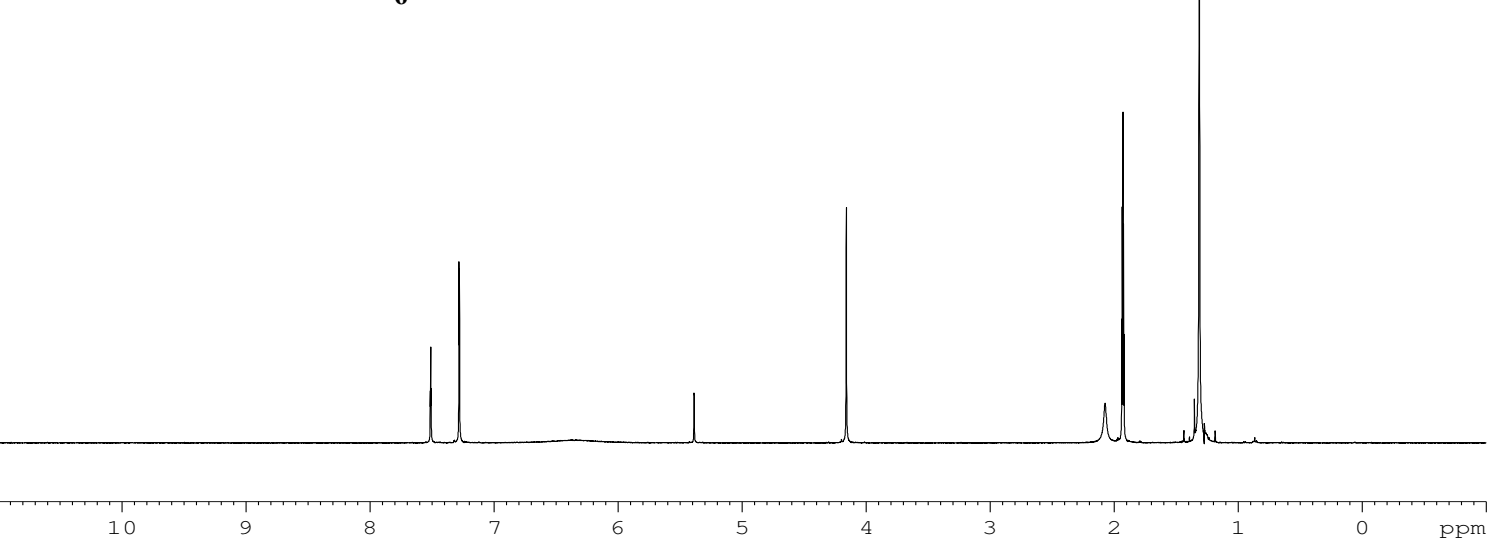




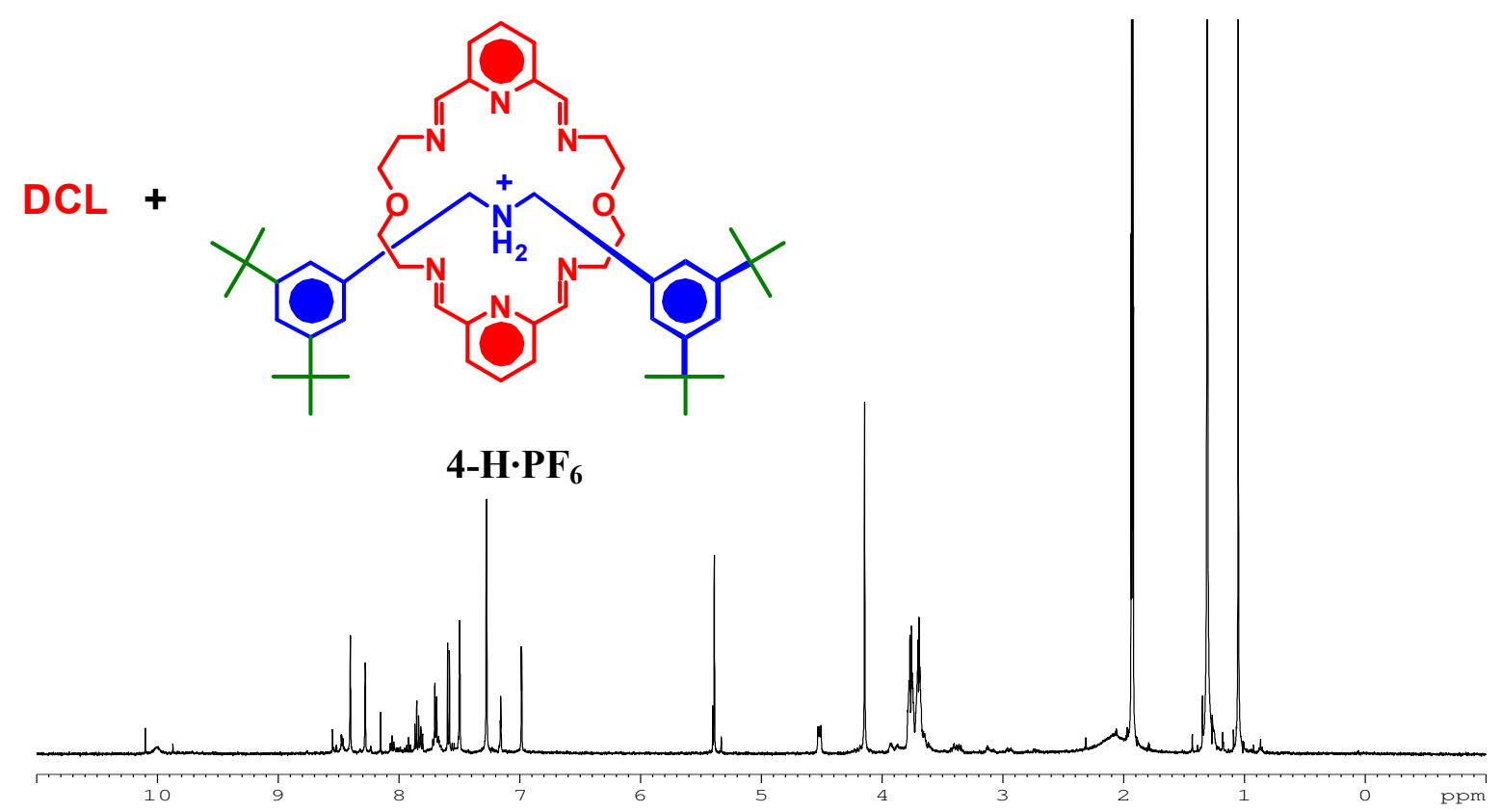

\section{D-NOESY ${ }^{1} \mathrm{H}$ NMR Spectrum ${ }^{\mathrm{S} 1}$ of $3-\mathrm{H} \cdot \mathrm{PF}_{6}$}

A NOESY experiment ${ }^{\mathrm{S} 1}$ (Figure $\mathrm{S} 1$ ) was performed on an equilibrating mixture of 1$\mathrm{H} \cdot \mathrm{PF}_{6}$, the DCL, and $\mathbf{3}-\mathrm{H} \cdot \mathrm{PF}_{6}$.

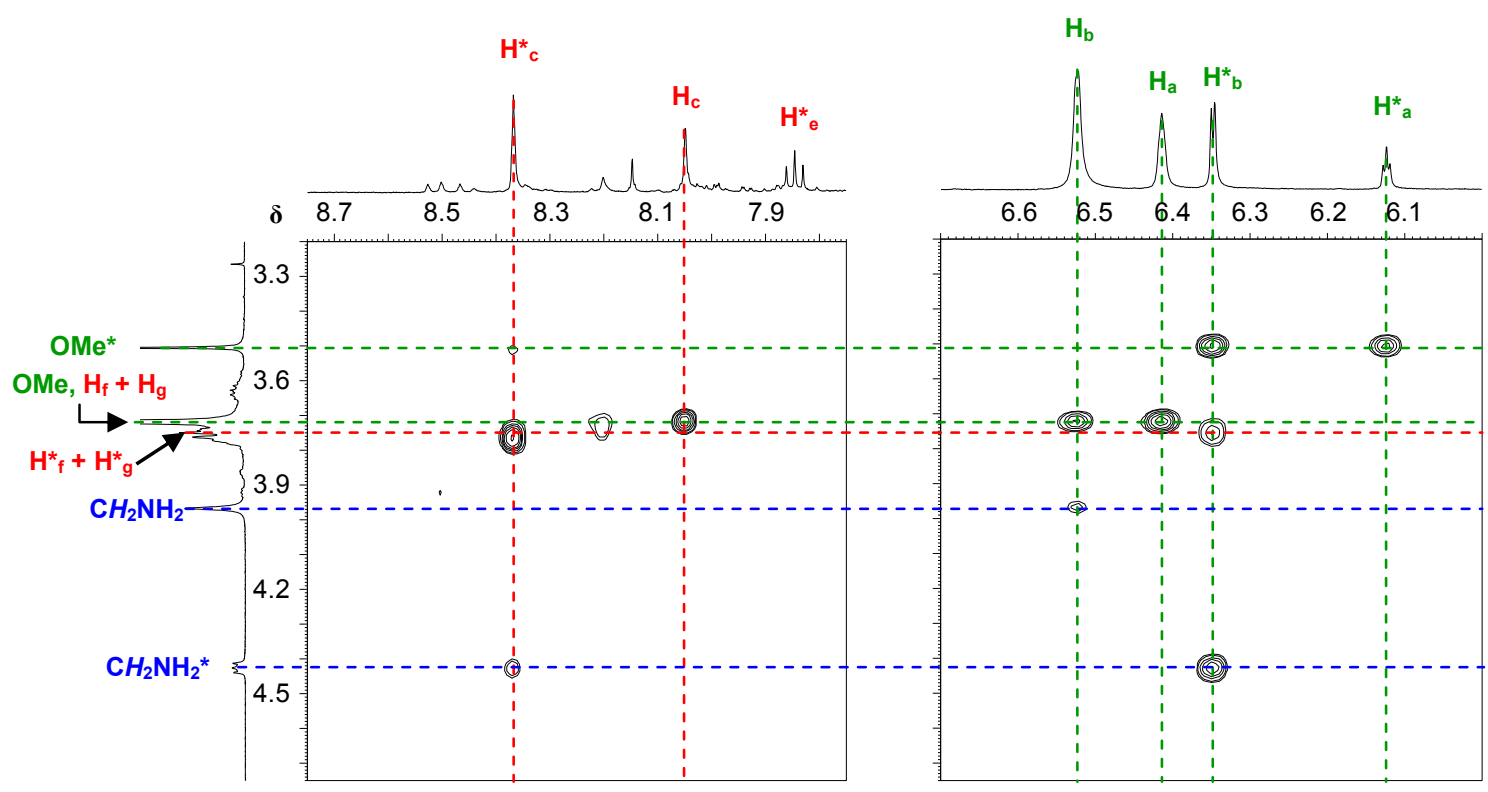

Figure S1 A 2D-NOESY spectrum of the crude reaction mixture containing 1$H \cdot P F_{6}$, the $D C L$, and $3-H \cdot P F_{6}$. Of note are the crosspeaks between the macrocyclic (shown in red) and dumbbell components (in blue or green) of 3$\mathrm{H} \cdot \mathrm{PF}_{6}$. 


\section{Variable-Temperature ${ }^{1} \mathrm{H}$ NMR Spectroscopic Data and Methods}

In order to glean thermodynamic information about the equilibrium between the dumbbell compound $2-\mathrm{H} \cdot \mathrm{PF}_{6}$, the $\mathbf{D C L}$, and $4-\mathrm{H} \cdot \mathrm{PF}_{6}$, we performed a variable temperature ${ }^{1} \mathrm{H}$ NMR experiment upon the mixture thereof. Upon cooling down the mixture, we found that integration of the area under the peaks, corresponding to complexed species, increase relative to their "free" counterparts. By dividing the standardized integration ${ }^{\mathrm{S} 4}$ of the area under peaks arising from complexed compounds by that of the "free" ones, we were able to obtain effective association constants ( $\left.K_{\text {eff }}\right)$ for the binding of the $[2+2]$ macrocyclic component of the $\mathbf{D C L}$ with dumbbell $\mathbf{2}-\mathrm{H} \cdot \mathrm{PF}{ }_{6}$ to produce [2] rotaxane $4-\mathrm{H} \cdot \mathrm{PF}_{6}$ at several temperatures. ${ }^{\mathrm{S} 5}$ This procedure was performed on the two peaks that were most easily identified in the ${ }^{1} \mathrm{H}$ NMR spectra - namely, the benzylic methylene protons and $\mathrm{H}_{\mathrm{b}}$ on the dumbbell. Then, the two resulting $K_{\text {eff }}$ constants (one from each set of signals) were averaged to give a mean $\mathrm{K}_{\text {eff }}$ for the system at each temperature. Finally, $\Delta H$ and $\Delta S$ were calculated from the graph of $\ln$ (average $\left.K_{\text {eff }}\right)$ versus $\mathrm{T}^{-1}$. The data for $K_{\text {eff }}$ at each temperature are presented in Table S1.

Table S1 Variable Temperature ${ }^{1} \mathrm{H}$ NMR spectroscopic data for the "complexation" of $2-\mathrm{H} \cdot \mathrm{PF}_{6}$ with the $\mathrm{DCL}$ to produce [2] rotaxane $4-\mathrm{H} \cdot \mathrm{PF}_{6}$ in $\mathrm{CD}_{2} \mathrm{Cl}_{2} / \mathrm{CD}_{3} \mathrm{CN}(2: 1)$

\begin{tabular}{cccc}
\hline$T(K)$ & $K_{\text {eff }}\left(\right.$ based on $\left.\mathrm{CH}_{2} \mathrm{NH}_{2}^{+}, M^{-1}\right)$ & $K_{\text {eff }}\left(\right.$ based on $\left.\mathrm{H}_{b}, M^{-1}\right)$ & $K_{\text {eff }}$ (average, $\left.M^{-1}\right)$ \\
\hline 321.7 & $1.3 \times 10^{2}$ & $1.5 \times 10^{2}$ \\
308.5 & $1.7 \times 10^{2}$ & $2.0 \times 10^{2}$ & $2.2 \times 10^{2}$ \\
299.9 & $2.4 \times 10^{2}$ & $2.5 \times 10^{2}$ & $2.8 \times 10^{2}$ \\
298.3 & $3.2 \times 10^{2}$ & $3.2 \times 10^{2}$ & $3.4 \times 10^{2}$ \\
284.1 & $3.5 \times 10^{2}$ & $4.5 \times 10^{2}$ & $4.9 \times 10^{2}$ \\
271.4 & $5.3 \times 10^{2}$ & $6.7 \times 10^{2}$ & $7.2 \times 10^{2}$ \\
258.9 & $7.7 \times 10^{2}$ & $1.1 \times 10^{3}$ & $1.2 \times 10^{3}$ \\
244.6 & $1.2 \times 10^{3}$ & $4.9 \times 10^{3}$ & $5.2 \times 10^{3}$ \\
230.1 & $5.4 \times 10^{3}$ & $4.6 \times 10^{3}$ & $4.8 \times 10^{3}$ \\
\hline
\end{tabular}




\section{Crystal Structure Packing Diagram of the $[2+2]$ Macrocyclic Member of the DCL}

The ball-and-stick representation of the packing diagram of the $[2+2]$ macrocycle, obtained from a crystal grown from an equilibrating mixture of $\mathbf{1}-\mathrm{H} \cdot \mathrm{PF} \mathrm{F}_{6}$, the $\mathbf{D C L}$, and 3$\mathrm{H} \cdot \mathrm{PF}_{6}$, is shown in Figure S2. All attempts to crystallize any member of the DCL without the template present were unsuccessful. CCDC-635863 contains the supplementary crystallographic data for this molecule. These data can be obtained free of

charge from the Cambridge Crystallographic Data Centre via www.ccdc.cam.ac.uk/data_request/cif.

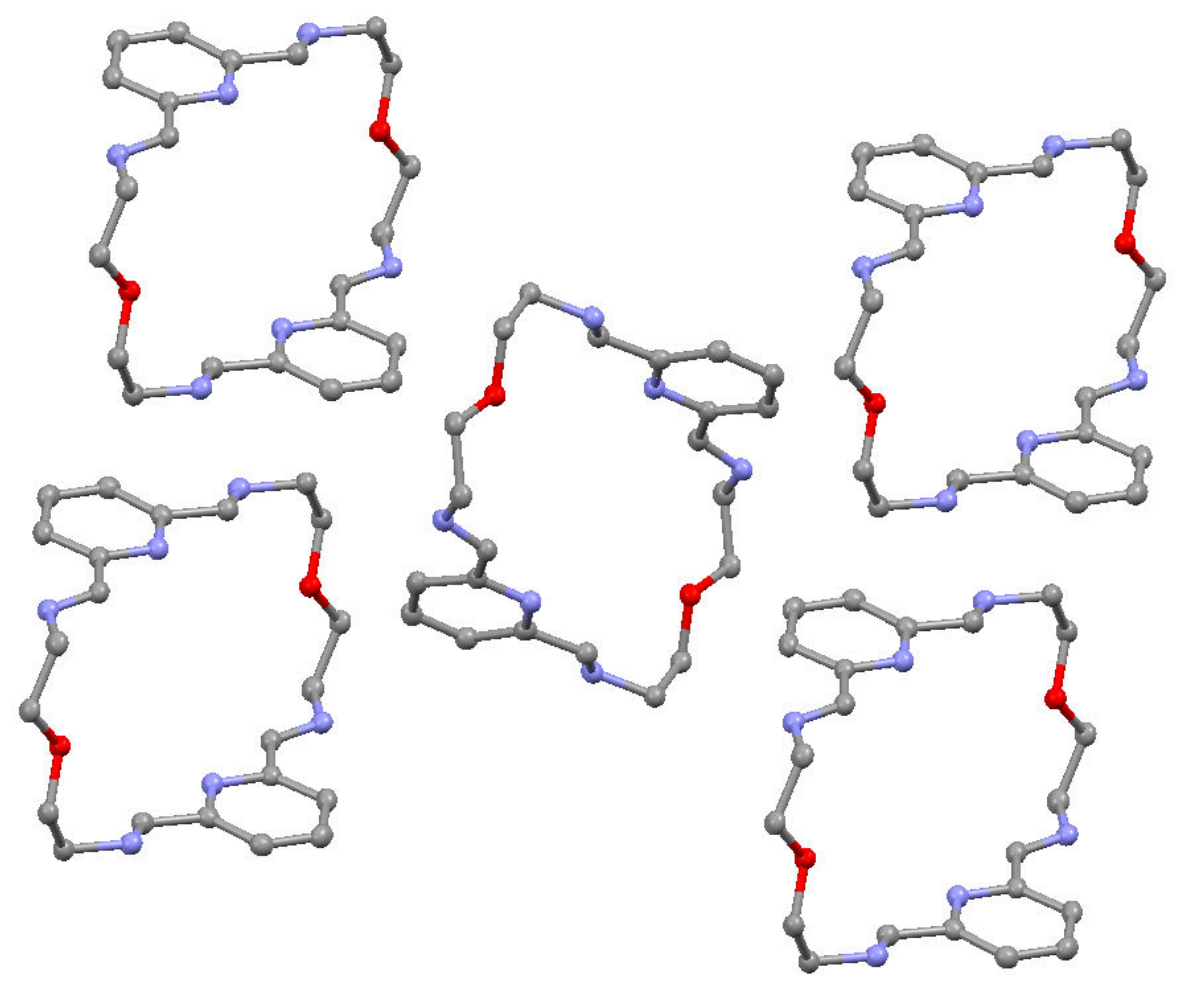

Figure S2 Crystal packing diagram of the [2 + 2] macrocyclic member of the DCL 
S1 Friebolin, H. Basic One- and Two-Dimensional NMR Spectroscopy, WileyVCH, Weinheim, 1998.

S2 Glink, P.T.; Oliva, A.I.; Stoddart, J.F.; White A.J.P.; Williams, D.J. Angew. Chem. 2001, 113, 1922-1927; Angew. Chem. Int. Ed., 2001, 40, 1870-1875.

S3 Nabeshima, T.; Nishida D.; Saiki, T. Tetrahedron, 2003, 59, 639-647.

S4 In order to avoid inconsistencies when comparing one spectrum at one temperature to another at a different temperature, all integrations were divided by the area under the peak of the residual $\mathrm{CD}_{3} \mathrm{CN}$ solvent, whose relative concentration remained constant throughout the entire process.

S5 Because absolute values for certain concentrations of "free" species cannot be determined from the NMR spectra, certain assumptions were made in order to simplify the calculations for Keff. For a detailed discussion of this issue, see Ref. S2 and Horn, M.; Ihringer, J.; Glink, P. T.; Stoddart, J. F. Chem. Eur. J., 2003, 9, 4046-4054. 